\title{
Development of transgenic rice lines expressing the human lactoferrin gene
}

\author{
Jin-Hyoung Lee $\cdot$ II-Gi Kim $\cdot$ Hyo-Sung Kim $\cdot$ Kong-Sik Shin $\cdot$ Seok-Cheol Suh $\cdot$ Soon-Jong Kweon • \\ Seong-Lyul Rhim
}

Received: 15 November 2010 / Accepted: 29 November 2010

(c) Korean Society for Plant Biotechnology

\begin{abstract}
Lactoferrin is an $80-\mathrm{kDa}$ iron-binding glycoprotein that is found in high concentrations in human milk. Human lactoferrin $(h L F)$ has several beneficial biological activities including immune system modulation and antimicrobial activity. In the present study, we devolved a method of $h L F$ expression through introducing the $h L F$ gene construct into Oriza sativa cv. Nakdong using the Agrobacterium-mediated transformation system. The expression of the $h L F$ gene under the control of the rice glutelin promoter was detected in the seeds of transgenic rice plants. Transformed rice plants were selected on media containing herbicide(DL-phosphinothricin) and the integration of $h L F$ cDNA was confirmed by Southern blot analysis. The expression of the full length hLF protein from the grains of transgenic rice plants was verified by Western blot analysis. The lactoferrin expression levels in the transformed rice grains determined by enzyme-linked immunosorbant assay accounted for approximately $1.5 \%$ of total soluble protein. Taken together, these data indicate that rice grains expressing hLF can be directly incorporated into infant formula and baby food.
\end{abstract}

Keywords human lactoferrin gene, rice, transgenic plants

\section{Introduction}

Lactoferrin is an iron-binding, multifunctional glycoprotein that is found in high concentrations in human milk. Human

J.-H. Lee $\cdot$ H.-S. Kim • K.-S. Shin · S.-C. Suh • S.-J. Kweon National Academy of Agricultural Science, Rural Development Administration, Suwon, Gyeonggi-do 441-707, Korea

I.-G. Kim $\cdot$ S.-L. Rhim $(\bowtie)$

Department of Biomedical Science, Hallym University,

Chuncheon, Gangwon-do 200-702 Korea

e-mail: slrhim@hallym.ac.kr lactoferrin $(h L F)$ has several biological activities including protection from pathogens, immune system modulation, regulation of iron absorption, antimicrobial activity, and promotion of cellular growth (Arakawa et al. 1999; Lönnerdal 1996).

Human milk-fed infants are healthier than formula-fed infants (Hanson and Korotkova 2002), which may in part be due to the lack of important components including HLF in infant formula. The potential of lactoferrin to act both as an antimicrobial and an immune regulatory agent in addition to its nutritional and pharmaceutical value has stimulated considerable interest in the development of its expression, which may provide the beneficial factors present in human milk when added to infant formula. Recombinant (rhLF) has been produced in various systems, including fungi (Ward et al. 1992), transgenic yeast (Liang and Richardson 1993), mice (Platenburg et al. 1994), and cows (Van Berkel et al. 2002). However, both animal and fungal production systems require a high degree of purification as well as safety and toxicity testing prior to use as a food additive or in infant formula (Chong and Langridge 2000; Nandi et al. 2002). In contrast, when expressed in transgenic plants, lactoferrin can be directly incorporated into food additives without the purification of rhLF, providing a convenient advantage over these other expression systems. The expression of rhLF in plants has been reported in tobacco (Salmon et al. 1998), potato (Chong et al. 1997), tomato (Lee et al. 2002), rice (Nandi et al. 2002), and sweet potato cell culture systems (Min et al. 2006).

There are several distinct advantages of expressing rhLF in rice (Nandi et al. 2005). Rice is generally regarded as safe (GRAS) for consumption and rice-based foods are considered hypoallergenic. Thus, rice grains expressing rhLF may be processed for use in infant formula without extensive purification steps. In the present study, we expressed the full length rhLF gene under the control of a rice glutelin 
promoter in the japonica type rice cultivar, Oryza sativa $L$. cv. NakDong.

\section{Materials and methods}

Plant material, regeneration, and culture conditions

Mature seeds of rice (Oryza sativa L. cv. Nakdong) were surface-sterilized in $70 \%$ ethanol for $5 \mathrm{~min}$, then in $2 \%$ sodium hypochlorite for $15 \mathrm{~min}$, and washed five times in sterile distilled water. The seeds were then cultured on N6 callus induction medium (Chu et al. 1975) containing 2 $\mathrm{mg} / \mathrm{L} 2,4-\mathrm{D}$ and incubated at $28^{\circ} \mathrm{C}$ in darkness for three weeks. The calli derived from scutella of seeds were subcultured in fresh $\mathrm{N} 6$ medium at $28^{\circ} \mathrm{C}$ in darkness for three days. Actively growing pieces of calli were used for rice transformation.

\section{Construction of $h L F$ rice expression vector}

The plasmid $\mathrm{p} H L F$ containing the $2.1 \mathrm{~kb}$ full length $h L F$ cDNA fragment was kindly provided by Prof. Pauline Ward (Baylor College of Medicine, Houston, Texas, USA). The $h L F$ cDNA was digested with HindII-HindIII and the fragment cloned into the pBluescript II KS plasmid (pBKS$h L F)$. The XhoI-SmaI fragment containing the rice glutelin promoter was isolated from $\mathrm{pBKS}-\mathrm{GB}$ and inserted into the XhoI-HindII sites of pBKS- $h L F$ (pBKS-Glu/hLF). The $X h o I-N o t$ I fragment containing the $h L F$ cDNA with the glutelin promoter was isolated from $\mathrm{pBKS}-\mathrm{Glu} / h L F$ and inserted into the pSB binary vector (pSBG- $h L F$ ) such that the vector contained the mature human lactoferrin gene under the control of the rice glutelin promoter, the PinII terminator, and the herbicide resistant bar gene as a selectable marker. The resulting plasmid (pSBG- $h L F$ ) was introduced into Agrobacterium tumefaciens strain LBA4404 using the tri-parental mating method (Simon 1984).
Generation of transgenic rice plants

Agrobacterium tumefaciens strain LBA4404 harboring the pSBG- $h L F$ plasmid was used for transformation. The Agrobacterium with pSBG- $h L F$ was grown overnight at $28^{\circ} \mathrm{C}$ in Luria-Bertani (LB) medium containing $10 \mathrm{mg} / \mathrm{L}$ tetracycline and $50 \mathrm{mg} / \mathrm{L}$ spectinomycin. The culture was centrifuged at $2500 \mathrm{rpm}$ for $15 \mathrm{~min}$, and the cell pellet re-suspended in $25 \mathrm{ml}$ of AAM medium (Philip and Bowler 2002) containing $200 \mu \mathrm{M}$ acetosyringone. The calli were then immersed in the bacterial suspension for $1 \mathrm{~h}$ at room temperature. Following incubation, the Agrobacterium cells were removed by blotting on sterile filter paper. The infected calli were transferred to N6 medium containing 200 $\mu \mathrm{M}$ acetosyringone and incubated in the dark for three days at $25^{\circ} \mathrm{C}$. After co-cultivation, the infected calli were washed five times with sterile water containing $250 \mathrm{mg} / \mathrm{L}$ carbenicillin, placed on MS selection medium (MS slats and vitamins, 100 mg/L myo-inositol, $1 \mathrm{mg} / \mathrm{L}$ L-proline, $500 \mathrm{mg} / \mathrm{L}$ L-alanine, $300 \mathrm{mg} / \mathrm{L}$ casein enzymatic hydrolysate, $2 \mathrm{mg} / \mathrm{L}$ 2,4-D, 30 $\mathrm{g} / \mathrm{L}$ sucrose, $3 \mathrm{~g} / \mathrm{L}$ phytagel, $250 \mathrm{mg} / \mathrm{L}$ carbenicillin, and 6 $\mathrm{mg} / \mathrm{L}$ DL-phosphinothricin), and cultured at $28^{\circ} \mathrm{C}$ in darkness for two to three weeks. Following the cultivation, healthy green shoots were selected and transferred to MS regeneration medium (MS salts and vitamins, $1 \mathrm{mg} / \mathrm{L} \mathrm{NAA,}$ $5 \mathrm{mg} / \mathrm{L}$ kinetin, $30 \mathrm{~g} / \mathrm{L}$ D-sorbitol, $15 \mathrm{~g} / \mathrm{L}$ maltose, $4 \mathrm{~g} / \mathrm{L}$ phytagel, and $3 \mathrm{mg} / \mathrm{L}$ DL- phosphinothricin) for full plant formation with an extensive root system. Following rooting, the transgenic plants were transferred to a greenhouse and grown to maturity.

Detection of the lactoferrin gene in transgenic rice plants

Total genomic DNA was extracted from the young leaves of the transgenic rice using CTAB extraction methods (Murray and Thompson 1980). For Southern blot analysis, $5 \mu \mathrm{g}$ of genomic DNA were digested with the $\mathrm{BamHI}$ restriction enzyme. The digested DNAs were electrophoresed on $1 \%$

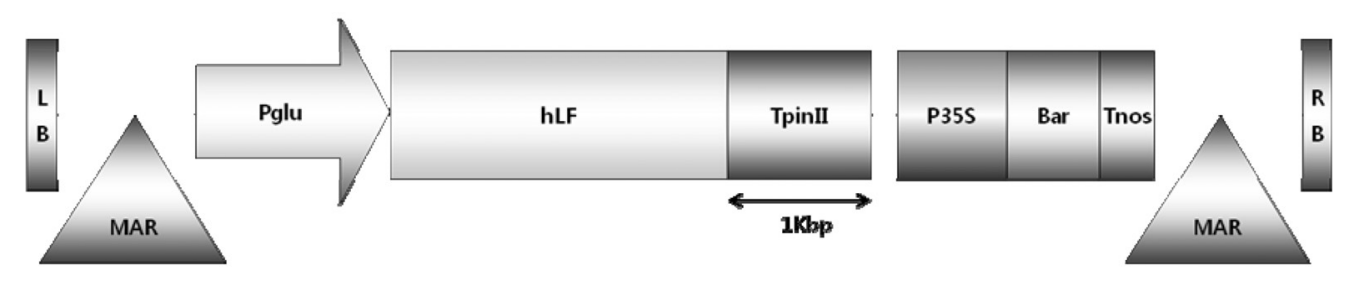

Fig. 1 Partial map of the pSBG- $h L F$ binary vector harboring the human lactoferrin gene.

Pglu: rice glutelin promoter; $h L F$ : human lactoferrin cDNA; TpinII: proteinase inhibitor II terminator; P35S: CaMV 35S promoter; Bar: phosphinothricin acetyltransferase gene; Tnos: nopaline synthase terminator; MAR: matrix attachment region; LB and RB: T-DNA left and right borders, respectively 
agarose gels, blotted onto nylon membranes (Hybond-N+, GE Healthcare), and hybridized to $1 \mathrm{~kb}$ of the $h L F$ cDNAspecific probe. The probe was labeled with [a-32P]dCTP using Ready-to-go DNA labeling beads (GE Healthcare). Hybridization was performed in hybridization solution ( $1 \%$ BSA, 1 mM EDTA, $0.5 \mathrm{M} \mathrm{NaPO}_{4}$, pH 7.2, 7\% SDS, 1 $\mathrm{mg} / \mathrm{ml}$ salmon sperm DNA) at $65^{\circ} \mathrm{C}$ overnight. Following hybridization, the blot was washed with washing solutions $\left(1^{\text {st }}\right.$ solution, $2 \times \mathrm{SSC}, 0.1 \% \mathrm{SDS} ; 2^{\text {nd }}$ solution, $1 \times \mathrm{SSC}, 0.1 \%$ $\mathrm{SDS} ; 3^{\text {rd }}$ solution, $0.2 \times \mathrm{SSC}, 0.1 \% \mathrm{SDS}$ ) at $65^{\circ} \mathrm{C}$ for $15 \mathrm{~min}$ per solution. The membranes were then exposed to X-ray film (Fuji Photo Film).

Immunoblot detection of lactoferrin proteins in transgenic rice plants

Total soluble proteins were extracted from the seeds of transgenic rice plants by grinding in the presence of the protein extraction buffer $(50 \mathrm{mM}$ Tris- $\mathrm{HCl} \mathrm{pH} 7.5,1 \%$ 2-mercaptoethanol, 10\% glycerol, $1 \mathrm{mM}$ PMSF, and 2\% PVPP). The homogenate was centrifuged at $14,000 \mathrm{rpm}$ for $20 \mathrm{~min}$ at $4^{\circ} \mathrm{C}$. The soluble protein concentration in the extracts was then determined (Bradford 1976). Approximately $20 \mu \mathrm{g}$ total protein from each sample were loaded onto $8 \%$ $(\mathrm{v} / \mathrm{v})$ SDS-polyacrylamide gels along with $100 \mathrm{ng}$ of commercially available lactoferrin (Sigma) as a standard. The protein bands were separated by polyacrylamide gel electrophoresis, and transferred onto PVDF membranes (GE Healthcare) through electroblotting with a Mini Trans-Blot ${ }^{\circledR}$ (Bio-Rad). The membranes were blocked in 5\% skim milk in TBST buffer (10 mM Tris-HCl pH 7.5, $150 \mathrm{mM} \mathrm{NaCl}$, and $0.1 \%$ Tween 20 ) for $1 \mathrm{~h}$ at room temperature. The blocked membrane was probed with rabbit anti- $h L F$ antibodies (Sigma) followed by detection using a goat anti-rabbit IgG alkaline phosphatase conjugate (Sigma). The recombinant protein was visualized by colorimetric reaction in which the membrane was incubated in a BCIP/NBT (5bromo-4-chloro-3-indolyl phosphate/nitroblue tetrazolium) substrate solution until the positive control standard was clearly evident.

Determination of lactoferrin content in transgenic rice grains

The transgenic rice grains ( $1 \mathrm{~g}$ fresh weight) were homogenized on ice with a mortar in a double volume (w/v) of cold extraction buffer ( $50 \mathrm{mM}$ Tris- $\mathrm{HCl}, \mathrm{pH} 7.5)$ and centrifuged at $14,000 \times \mathrm{g}$ for $15 \mathrm{~min}$ at $4^{\circ} \mathrm{C}$. The total soluble protein concentration in the homogenate supernatant was determined using the Bradford method. The content of recombinant hLF from transformed and non-transformed rice plants was assessed by enzyme-linked immunosorbant assay (ELISA) according to the BioxyTech Lactof-EIA protocol (OxiResearch).

\section{Results and discussion}

Generation of transgenic rice plants

Rice calli were transformed using $A$. tumefaciens carrying the pSBG- $h L F$ binary vector (Fig. 1). The transformation vector contains the mature human lactoferrin gene under the control of the rice glutelin promoter, a PinII terminator, and the herbicide resistant bar gene as a selectable marker. The infected calli were initially cultured in MS selection medium containing $250 \mathrm{mg} / \mathrm{L}$ carbenicillin and $3 \mathrm{mg} / \mathrm{L}$ DL-phosphinothricin and the shoots differentiated from transformed calli (Fig. 2A). Resistant shoots were transferred onto MS regeneration medium containing $250 \mathrm{mg} / \mathrm{L}$ carbenicillin and $3 \mathrm{mg} / \mathrm{L} \mathrm{PPT}$ and cultured for an additional three weeks. All the shoots grew well and rooted in the medium (Fig. 2B). Thirty-four independent PPT-resistant rice plants were transferred to pots and grown in a greenhouse (Fig. 2C). The plants regenerated and grew in a comparable fashion to the non-transgenic wild-type plant.

Basta spray assays were conducted to evaluate the functional

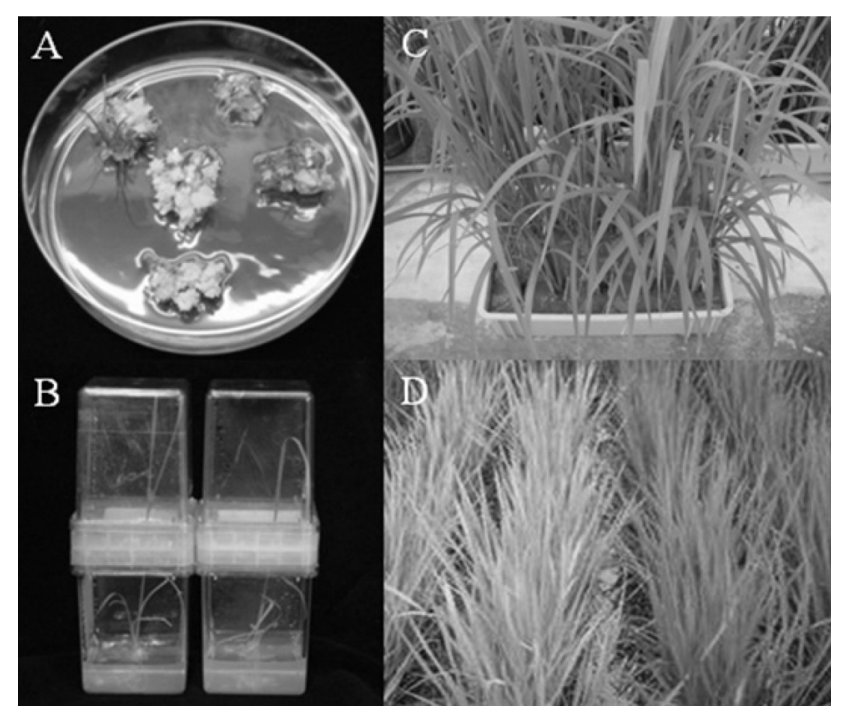

Fig. 2 Formation and expression of the bar gene in transgenic rice plants. A: Shoot induction from the DL-phosphinothricinresistant embryogenic calli; B: Development of independent transformants in the regeneration medium; $\mathrm{C}$ : Transgenic rice plants growing in the green house; D: Comparison of transgenic rice showing Basta resistance with wild-type plants. Transgenic plants grown for 60 days in the field were sprayed (on the leaves) with $3 \mathrm{~g} / \mathrm{L}$ of the herbicide (Basta). The photograph shows the plants one week after the spraying 
bar gene expression in putative $\mathrm{T}_{1}$ transgenic rice plants in a GMO field. When sprayed with Basta $(3 \mathrm{~g} / \mathrm{L})$, the transformants showed complete resistance to the herbicide, while the non-transformed wild-type plants became withered and eventually died within two weeks of treatment (Fig. 2D). These results confirmed the successful insertion of the Bar gene into the genome of the transgenic rice plants.

Detection of the $h L F$ gene in transgenic rice plants

To confirm the stable integration of the $h L F$ gene into the nuclear genome of host cells, Southern blot analysis was performed with 25 independent $\mathrm{T}_{0}$ transgenic lines that produced $\mathrm{T}_{1}$ seeds, using the ${ }^{32} \mathrm{P}$-labeled $h L F$ cDNA fragment as a probe. As shown in Fig. 3, 22 transgenic rice plants showed a clear band of the expected $2.1 \mathrm{~kb}$ length, indicating that the $h L F$ gene was correctly incorporated into the genomic DNA of the plant. No hybridization signal was observed in genomic DNA from control plants or the remaining three lines (Fig. 3, lanes 1, 7, and 26).

Expression of the lactoferrin protein in transgenic rice plants

Four representative $T_{3}$ transgenic rice lines were selected by southern blot analysis and agronomic characteristics. These lines were analyzed for the expression of the rhLF protein through Western blot analysis. The rhLF protein synthesized in the grains of transgenic plants is shown in Fig. 4. The rhLF proteins (Fig. 4, lanes 2-5) migrated as a single band at the expected molecular weight of approximately $80 \mathrm{kDa}$,
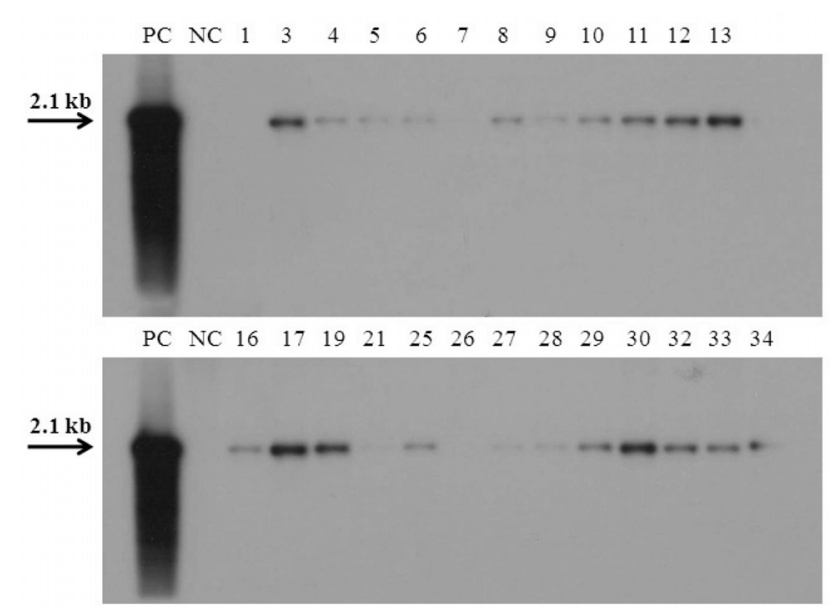

Fig. 3 Southern blot analysis of transgenic rice plants carrying the $h L F$ gene. Total genomic DNA ( $5 \mu \mathrm{g}$ ) from 25 representative transgenic rice plants was digested with BamHI. The blot was probed with a $1 \mathrm{~kb} h L F$ gene fragment. Lane PC: plasmid DNA digested with the same enzymes; NC: non-transformed negative control; lanes 1-34: transgenic rice plants indicating that full length lactoferrin was synthesized in the transgenic rice plants. Extracts from the untransformed plants did not react with the anti-lactoferrin antibody (Fig. 4, lane 1).

Recombinant $\mathrm{hLF}$ contents in transgenic rice grains

Transgenic rice plants containing $h L F$ cDNA were screened for the expression levels of recombinant lactoferrin using ELISA. The results of indirect ELISA experiments demonstrated that all transgenic plants expressed variable levels of the recombinant rhLF protein in grains. The levels of rhLF detected varied from $0.63 \%$ of soluble protein to $1.51 \%$ (Fig. 5). The wild-type rice plant did not express the rhLF protein.

A previous study reported that rhLF was expressed in rice at significantly higher levels than in other transgenic plant systems, reaching $0.5 \%$ of the grain weight (Nandi et al. 2002). Furthermore, the expression of rhLF in Nicotiana benthamiana and tobacco cell cultures reportedly achieved

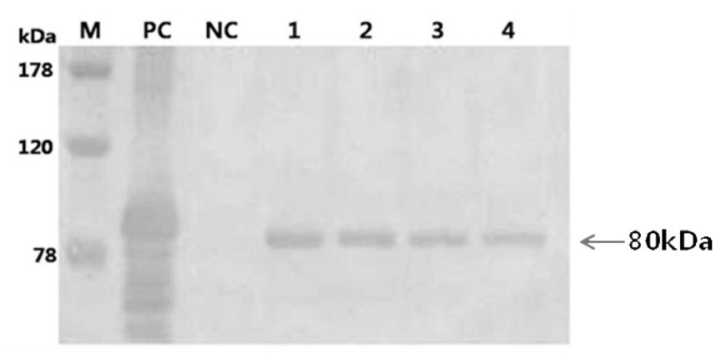

Fig. 4 Immunodetection of human lactoferrin protein synthesized in the grains of transgenic rice plants. Twenty micrograms of total soluble protein from transgenic rice grains were resolved by SDS-PAGE and membranes were probed with anti-lactoferrin antibodies. The arrow indicates the hLF protein synthesized in the transgenic rice plants. Lane M: molecular weight marker; lane PC: commercially available hLF as standard; lane NC: non-transformed negative control; lanes 1-4: transgenic rice lines (pGF 5-1-1, 11-1-1, 13-1-1, 29-1-1, and 32-2-1)

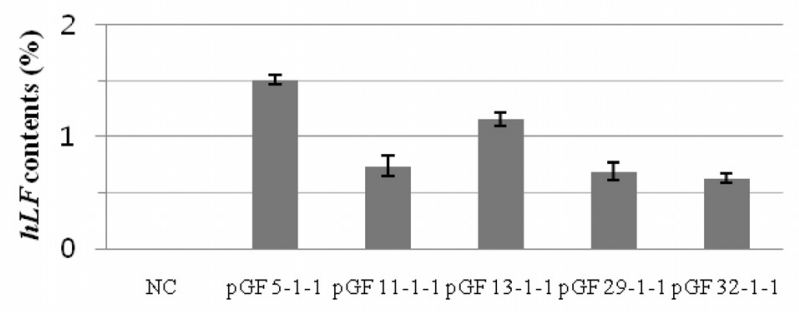

Fig. 5 Levels of recombinant hLF protein in the grains of transgenic rice plants. Total soluble proteins were extracted from the grains of transgenic rice plants. Approximately $1 \mu \mathrm{g}$ protein was analyzed by ELISA. Experiments were repeated three times. NC: non-transformed rice plant; pGF5-1-1, 11-1-1, 13-1-1, 29-1-1, and 32-2-1: transgenic rice plants 
levels of 0.6 and $4.3 \%$ of the total soluble protein, respectively (Choi et al. 2003; Li et al. 2004). However, the rhLF protein from tobacco or non-edible plants requires extensive purification before it can be considered for any food application, making it an unlikely commercially viable product (Lönnerdal 2002). In contrast, as rice is safe (GRAS) for consumption and rice-based foods including rice-based infant formulas are considered to be hypoallergenic, the expression of rhLF in rice seeds could contribute to the production of a nutritional hLF supplement for non-breast fed infants as well as children and adults. In addition, the expression of recombinant $\mathrm{hLF}$ in seeds enables long-term storage at ambient temperature as the protein accumulates in a stable form.

In conclusion, we confirmed the expression of the $h L F$ gene in transgenic japonica rice cv. Nakdong obtained through Agrobacterium-mediated transformation. The $h L F$ gene was integrated into the genomic DNA of transgenic rice plants and expressed in the grains of these plants. The expression levels of recombinant hLF represented up to $1.5 \%$ of the total soluble protein in transgenic rice grains. Based on these results, four $T_{3}$ lines were advanced to $T_{4}$ generations in a GMO field. At present, we are conducting molecular analysis to confirm the gene copy number for the selection of homozygous lines with agronomic characteristics similar to those of non-transformants. This study demonstrates the use of transgenic japonica rice cv. Nakdong in applications for human biological functions, efficacy, and safety.

\section{Acknowledgements}

This research was supported by grants from Hallym University Research Fund, 2008 (HRF-2008-024), the National Academy of Agricultural Science (200902 FHT020815020), the Rural Development Administration and by grants from the Ministry of Education, Science and Technology, Korea, through the Crop Functional Genomics Center (CG2141 to S.C. Suh).

\section{References}

Arakawa T, Chong DKX, Slattery CW, Langridge WHR (1999) Improvements in human health through production of human milk proteins in transgenic food plants. In: Shahidi F, Kolodziejczyk P, Whitaker JR (eds) Chemicals via Higher Plant Bioengineering, Kluwer Academic/Plenum Publishers, New York: 149-159
Bradford M (1976) A rapid and sensitive method for the quantitation of microgram quantities of protein utilizing the principle of protein-dye binding. Anal Biochem 72:248-254

Choi SM, Lee OS, Kwon SY, Kwak SS, Yu DY, Lee HS (2003) High expression of a human lactoferrin in transgenic tobacco cell cultures. Biotech Lett 25:213-218

Chong DKX, Langridge WHR (2000) Expression of full-length bioactive antimicrobial human lactoferrin in potato plants. Transgenic Res 9:71-78

Chong DKX, Roberts W, Arakawa T, Illes K, Bagi G, Slattery CW, Langridge WHR (1997) Expression of the human milk protein $\beta$-casein in transgenic potato plants. Transgenic Res 6:289-296

Chu CC, Wang CC, Sun CS, Hsu C, Yin KC, Chu CY, Bi FY (1975) Establishment of an efficient medium for another culture of rice through comparative experiments on the nitrogen sources. Sci Sin 18:659-668

Hanson LA and Korotkova M (2002) The role of breastfeeding in prevention of neonatal infection, Seminars in fetal \& neonatal medicine. 7:275-281

Lee TJ, Coyne DP, Clemente TE, Mitra A (2002) Partial resistance to bacterial wilt in transgenic tomato plants expressing antibacterial lactoferrin gene. J Amer Soc Hort Sci 127:158164

Li Y, Geng Y, Song H, Zheng G, Huan L, Qiu B (2004) Expression of a human lactoferrin N-lobe in Nicotiana benthamiana with potato virus X-based agroinfection. Biotechnol Lett 26:953957

Liang Q, Richardson T (1993) Expression and characterization of human lactoferrin in yeast Saccharomyces cerevisiae. J Agric Food Chem 41:1800-1807

Lönnerdal B (1996) Recombinant human milk proteins-an opportunity and a challenge. Am J Clin Nutr 63:622S-626S

Lönnerdal B (2002) Expression of human milk proteins in plants. J Am Clin Nutr 21:218S-221S

Min SR, Woo JW, Jeong WJ, Han SK, Lee YB, Liu JR (2006) Production of human lactoferrin in transgenic cell suspension cultures of sweet potato. Biologia Plantarum 50:131-134

Murray M and Thopson WF (1980) Rapid isolation of molecular weight plant DNA. Nucleic Acid Res., 8:4321-5

Nandi S, Suzuki YA, Huang J, Yalda D, Pham P, Wu L, Bartley G, Huang N, Lönnerdal B (2002) Expression of human lactoferrin in transgenic rice grains for the application in infant formula. Plant Sci 163:713-722

Nandi S, Yalda D, Lu S, Nikolov Z, Misaki R, Fujiyama K, Huang N (2005) Process development and economic evaluation of recombinant human lactoferrin expressed in rice grain. Transgenic Res 14:237-249

Platenburg GJ, Kootwijk EP, Kooiman PM, Woloshuk SL, Nuijens JH, Krimpenfort PJ, Peeper FR, de Boer HA, Strijker $\mathrm{R}$ (1994) Expression of human lactoferrin in milk of transgenic mice. Transgenic Res 3:99-108

Philip MG, Bowler C (2002) Molecular plant biology volume one: a practical approach. Oxford University Press, Oxford: UK 258:17-23 
Salmon V, Legrand D, Slomianny MC, Yazidi IE, Spik G, Gruber V, Bournat P, Olagnier B, Mison D, Theisen M, Merot B (1998) Production of human lactoferrin in transgenic tobacco plants. Protein Express Purif 13:127-135

Simon R (1984) High frequency mobilization of gram negative bacterial replicons by the in vitro constructed Tn5-Mob transposon. Mol Gen Genet 196:413-420

Van Berkel PHC, Welling MM, Geerts M, Van Veen HA,
Ravensbergen B, Salaheddine M, Pauwels EKJ, Pieper F, Nuijens JH, Nibbering PH (2002) Large scale production of recombinant human lactoferrin in the milk of transgenic cows. Nature Biotechnol 20:484-487

Ward PP, May GS, Headon DR, Conneely OM (1992) An inducible expression system for the production of human lactoferrin in Aspergillus nidulans. Gene 122:219-223 